of a fragment of cartilage and bone taken by Sir J. Simon from the knee-joint three weeks after a wrench received in falling; and (2) the specimen figured by $\mathrm{Mr}$. Teale, ${ }^{9}$ which, with its rough (fractured) bony surface on one side, and articular cartilage on the other, as seen in the bottle, leaves no doubt, I think, that it was, as he concludes, broken off from the articular surface of the patella by the severe wrench which he describes. Possibly it was broken off by a violent wrench against the margin of the femoral condyle, and the St. Thomas's specimen may have been due to the same cause." In a letter in reply to one in which I drew the Professor's attention to my case, he writes: "Your specimen seems to me the most clear instance of a loose body caused directly by a blow."

Finally, I would repeat that the object of this paper is to add one more case to prove that loose bodies in joints do occasionally originate in an injury, and in no way to question Professor Humphry's opinion that the great majority of these bodies are derived from the synovial membrane after the manner which he has described.

Great Cumberland-place, w.

\section{CASES TREATED BY HYPNOTISM AND SUGGESTION.}

\section{BY CHARLES LLOYD TUCKEY, M.D., C.M. ABERD.}

LAST autumn I had the pleasure of watching for a fortmight the practice of Dr. Liébeault of Nancy, and was much struck by some of the cures I saw him effect by hypnotism and suggestion. Liébeault is the pioneer of the system which has during the last few years been so prominently brought before the profession by Bernheinoq, Charcot, Heidenhain and other eminent foreign physicians. The treatment is conducted at Nancy almost as a matter of routine, and is shorn of all mystery and objectionable surroundings. The power to bypnotise does not seem to belong to one person more than another, and probably any medical man will arrive at a fair amount of dexterity after a little practice. Lethargic and anzemic subjects are perhaps the most encouraging patients to begin with, and boys about the age of puberty seem especially susceptible. Though the majority of people can be influenced by hypnotism, only a small percentage arrive at the more intense stages which involve unconsciousness; and for therapeutic purposes a slight degree of languor or somnolence is sufficient. For example, of over a hundred patients of all ages and in all ranks of societv, I have only completely failed in twenty.three cases; but among the eighty influenced I found only seven who completely lost consciousness and were susceptible to the advanced phenomena described by Charcot as characterising "le grand hypnotisme." The induction of the hypnotic state is of course merely preliminary to the treatment by suggestion, and it appears to act by closing the channels of ordinary thought and directing the attention of the patient exclusively to the point indicated by the operator. The immense power of directed consciousness to influence the organs and functions is so often seen in practice, and has been so well shown by Dr. Hack Tuke and other observers, that we may well eredit it with most of the curative effects of the treatment. Faith on the patient's part is not required, but his hostility or mental preoccupation will render futile any attempts to hypnotise him; it is well, therefore, on every ground to act upon the warning given by Professor Beaumis : never to operate without the patient's formal consent, and in the presence of witnesses. The following cases were treated by hypnotic suggestion.

CASE 1. Insomnia.-A. T- electrician, aged thirtyfive, had suffered from sleeplessness for three years, as the result of shock after a severe accident. He invariably awoke at 3 A.M. whatever time he went to bed, and was unable to sleep again. He was a man of exceptional mental activity, and want of sleep had induced much nervou depression and dyspepsia.-Feb. lst: He was hypnotised, and at once fell into a slightly lethargic state (Liébeault's first stage), and the suggestion was made that he would sleep well that night and would not awake at the usual time, but that even if he did awake he would be able to

9 Brit, Med, Jour., May 26th, 1888, p. 1109. sleep again.-2nd: He awoke at 3 A.M., but almost at once went to sleep again. He was again hypnotised, and told to sleep steadily through the night.-3rd: He awoke about 4 o'clock in consequence of a noise in the street, but soon fell asleep again. -5th : He reported having had two good nights, and the suggestion was repeated. From this time he has remained a good sleeper, getting an average of eight hours' sleep every night, and his general health has greatly improved.

CASE 2. Chronic diarrhoca.-General B-_-aged seventytwo, came under hypnotic treatment on April 3rd. He had previously been attended by me for chronic diarrhoea, but without much effect, and the malady was generally considered quite incurable. It duted from the time of the Crimean war, and since then he had never passed less than four motions a day, and these were always thin and watery. Any excitement or emotion aggravated the condition, and the day previously to my visit he had been moved twelve times. $\mathrm{He}$ is a man of exceedingly nervous type, but enjoys fairly good general health for his age. Hypnotism produced very much the same effect on him as on the preceding patient-a slight lethargy. In this state his abdomen was gently rubbed and the suggestion made that he should in future have but two motions a day, and that they should be properly formed. On April 4th the patient reported three motions during the last twenty-four hours. He was again hypnotised, and the same suggestions were repeated. On the morning of April 5th he passed the first formed motion he had had for over twenty years, and from that time his bowels have continued to act regularly twice a day and the stools have been well formed and natural.

CASE 3. Paroxysmal sneezing.-F. H-, thirty-eight, lady's maid, suffered during the summer of 1888 from hay fever, and the fits of sneezing continued into the autumn, so that when I saw her on Oct. 4th she told me that every morning on awaking she was seized with a paroxysm, which lasted about an hour, during which time she sneezed about forty times, and discharged copiously from the eyes. In addition to this, for a few days she had suffered from pain after eating, flatulence, and constipation. She was hypnotised, and at once fell into a profound sleep (Liébeault's sixth stage). Her nose was rubbed, and the suggestion made that she should sneeze no more. The stomach was also rubbed, and the suggestions made for the regulation of the digestive functions. There was no need to repeat the operation, for the paroxysmal sneezing ceased forthwith, and the digestion became easy and painless. There has been no relapse.

CASE 4. Nocturnal enuresis.-Alice C- aged nineteen, a dressmaker, came under treatment on Jan. 15th. She was anæmic, highly nervous, and suffered from dysmenorrhoa. She had always been addicted to wetting the bed, and had never passed more than a few consecutive nights without doing so. The habit prevented her getting employ. ment and had resisted all treatment. The week before seeing me she had come out of hospital, where she had spent a month without benefit. She fell into the third or cataleptic degree of hypnotism, and was told that the habit was to be cured, and that she was to awake at 2 A.M. and leave her bed to void urine. - Jan. 16th : The night had passed without accident. She awoke about 2 A.M., left the bed as directed, and then slept until called in the morning. The treatment was repeated. On the 17th a similar report, but she had wet the bed on the night of the 18th. This was the last time the habit recurred, and she has since awoke spontaneously in the middle of the night and left the bed. The dysmenorrhoea at the same time has almost disappeared, and the general health and mental condition have improved.

CASE 5. Functional dysmenorrhcea.-A. T-, aged twenty.one, clerk, came under treatment on Oct. 10th, 1888. She suffered much from painful menstruation, and has done so since the function became established fouryears previously. The period was always delayed three or four days, and was scanty and light coloured. It lasted about three days, and was attended with excessive backache, languor, and frontal headache. She suffered also from gastralgia, constipation, and flatulence. After treating her for some time on general principles, she was hypnotised on March 15th, immediately after a period, and atonce fell into a profound sleep (Liébeault's sixth stage). Suggestions directed to the painless performance of the digestive and menstrual functions were made and were repeated two or three times a week for four weeks. The following period appeared on the twenty-ninth day, and 
was attended by but little pain or inconvenience. She was told to return in three weeks, and suggestions were then made regarding the next period. This came on twentyseven days after the last, and continued for four days. It was more abundant and healthy, and perfectly free from pain. Since that time she has continued regular, and there has been no dysmenorrhœa. The digestion soon became painless and natural, and the general health shows great improvement.

CASE 6. Tabes dorsalis.-H. F-, aged forty-seven, a gentleman's servant, came under hypnotic treatment on March 9th. His family history was good, and he had never drunk to excess or had syphilis. About five years ago he had what he called blood poisoning, and what appears to have been a severe attack of typhoid fever. He had been severely wounded in the leg in the Franco-German war, but had made a good recovery. About the beginning of 1888 he noticed his sight was failing, and at the same time the skin of parts of the back became numb. His bowels became constipated, and when moved with the help of purgatives the action was attended by so much colicky pain and vomiting as to confine him to bed for twenty-four hours afterwards. He suffered from frequent sharp lightning-light pains in the limbs and from neuralgia in the chest and back. The tongue was coated and dry; he had no appetite, and there was great mental depression. He had lost two stone in weight in twelve months, and presented an emaciated and cachectic appearance. He was unable to walk more than half a mile, and always felt tired. His pupils were contracted and almost insensible to light, and there was nearly complete atrophy of the right optic nerve with partial atrophy of the left. The reflexes were absent, but there was nothing ataxic in his gait. Extensive patches of local anæsthesia occupied almost the whole of the left thorax and the back, and also the nose and upper lip. He was hypnotised, and fell into the third stage. Suggestions were made as to his bowels, digestion, sleep, and pains, the parts at the same time being gently rubbed.-March 10th: Bowels had acted slightly after breakfast (the first natural relief for three months), and with but little pain. He had slept well and felt better. The treatment to be repeated. - 11th : Bowels acted again more freely and quite painlessly. Suggestions repeated. He was hypnotised daily until the end of March, and by that time his general health was found to be greatly improved. $\mathrm{He}$ enjoyed his food, hardly ever had any pain, and was able to walk four or five miles without fatigue. His sight, which was rapidly deteriorating previously to the treatment, had remained stationary, and was always somewhat clearer for some hours after each sitting. The patient is still under observation, and though the disease probably progresses, he is, as a rule, fairly comfortable and free from pain.

CASE 7. Torticollis.-W. T-, aged thirty-four, consulted me on March 3rd for rheumatism of the muscles of the neck, shoulders, and back. She was subject to rheumatism, and the present attack had appeared suddenly about two weeks before after exposure to wet and cold. She had been unable since that time to dress or undress herself, and the least movement of the head or upper extremities caused pain. The muscles were tender to the touch, but there was no swelling or constitutional disturbance. The patient was advised to try hypnotism, and with some reluctance, for she said she did not believe in it, she consented. In less than a minute she slept profoundly, and in this condition the affected muscles were well rubbed for two or three minutes and the head turned in various positions. Within five minutes of her being hypnotised she was aroused, and asked to move her head and arms freely. This she did without pain, but said there remained a slight stiffness. The stiffness continued until the following morning and then disappeared, and the symptoms did not recur.

CASE 8. Headache, restlessness, and uterine pain after confinement.-F. Y-, aged forty-three, was confined of her fifth child on Jan. 20th. She was anæmic, and had had much colicky pain, headache, obstinate constipation, and hrmorrhoids during the last two months of gestation. Delivery was tedious, and there was much hæmorrhage from the relaxed and insufficiently contracted uterus, and the placenta had to be removed as it remained adherent. The patient complained greatly of headache and restlessness after the placenta was removed; the uterus contracted but slowly, and there was much pain, in spite of hot douches and ergot. She knew nothing of hypnotism, and was directed to look at my forefinger, and to compose her mind as much as possible. In a few moments the eyelids began to twitch, and almost inmediately she closed the eyes and sank into a profound sleep, which lasted for four hours. She awoke greatly refreshed, and without headache or after pains. The operation was repeated daily, and she made an unusually good recovery.

CASE 9. Scrivener's palsy (partial).-Alice N-_, aged thirty, post-office clerk, came under treatment on Jan. 10th. She had been in post-office employment for fifteen years, and had had a great deal of writing and telegraphing to do. About four years previous to her visit she had begun to feel numbness and loss of power in the right forefinger and thumb after writing a tew lines, and this was followed by pain along the front of the forearm, extending to the elbow. This condition gradually became worse, and in 1888 she was for three months under electrical treatment at St. Bartholomew's Hospital, with temporary benefit. She was fairly well nourished and complained of no other symptoms. The grasp of the right hand was considerably weaker than that of the left, and there was some tenderness and soreness on pressure of the flexor muscles in the forearm. But the muscles were not wasted, and there was no hyper-sensitiveness apparent along the course of the nerve trunks. After writing four or five lines she complained of loss of power and numbness in the fingers, and pain in the forearm, and was obliged to. give her whole attention to holding the pen and to grasp it tightly. She was hypnotised, and immediately fell into a profound sleep. In this state the muscles were masséed, and the fingers forcibly extended and pulled out. She was told she would be able to write without pain or embarrassment, and that the hand and arm would soon gain power. In a few minutes she was awakened, and told to sit down and write a page of foolscap, and this she did almost without fatigue. The treatment was repeated three times a week for a month, and she then reported herself quite cured. All tenderness and stiffness of the muscles had disappeared, and the grasp of the right hand was at least equal to that of the left. She has since continued well, and is able to write many hours a day without inconvenience.

CASE 10. Dipsomania.-L. G-, a gentleman of position, who was intensely anxious to be cured, was under my care during the month of January. His case was a bad one, and for three years had been getting worse. Uncontrollable fits of craving for spirits recurred every two or three weeks, and indulgence for three or four days was followed by intense nervous depression. $\mathrm{He}$ was hypnotised twice daily, and, like most of these patients, he was a very susceptible subject. Suggestions were always made that he should look upon spirits and intoxicating liquors generally with dislike, and that he should have no craving or wish for them. Under this treatment his appetite soon became very good, he slept well at night, and recovered his spirits. In four weeks he was able to return to his family, and he writes at intervals, telling me that, in spite of exceptional temptation, he has no inclination to taste alcohol or break his promise to me.

Notes to cases. - 1. The treatment of sleeplessness by suggestion is one of the triumphs of the system, and when this symptom occurs in almost any disease it at least can nearly always be removed if the patient is susceptible to hypnotism. 2. The same remarks apply to chronic constipation and diarrhœa and their treatment by suggestion. 3. The success of suggestion in this case seems to point to its use in hay fever-at least, when of a purely neurotic type; and Dr. Van Eeden of Amsterdam tells me he had several successes in treating this malady last summer. 4. The physicians practising hypnotism make a strong point of its success in nocturnal enuresis, and, in fact, consider it specific in functional disturbance of the urinary system. It is of great importance to make the patient promise not to wet the bed. 5. I have here given a case of functional dysmenorrhoea only, yet it is certain that when painful menstruation depends upon a well-defined pathological condition it may often be affected beneficially by suggestion. In one of my cases menstruation was attended by pain in the back, bearing-down ovarian irritation, occipital headache, and giddiness. All these symptoms have disappeared, though the state of uterine subinvolution remains, as shown by the sound passing nearly four inches. 6. This case is interesting, as showing the power of suggestion to relieve pain and other symptoms in organic disease. How great the relief may be is shown by a case reported at 
great length by Professors Fontain and Sigard of Toulon, 1 where a man in an advanced stage of disseminated sclerosis of the cord was so benefited as to be enabled to leave the hospital. The diagnosis was verified, as the patient returned within a year and died of tuberculosis. An elaborate necropsy revealed very extensive patches of sclerosis and render the improvement in the symptoms a remarkable feature of the case. 7 . In rheumatic torticollis, lumbago, and sciatica, hypnotic suggestion acts very satisfactorily, and in many cases of chronic rheumatism great improvement results from the patient employment of hypnotism combined with massage. 8. It appears as if hypnotism will prove a most useful auxiliary in the lying-in room. Several observers relate cases in which women have been painlessly confined under its influence, and it may often be employed to relieve after pains and to procure sleep. The mental condition induced by the combined mental strain and loss of blood render the puerperal woman especially susceptible to hypnotism. 9. In the treatment of writer's cramp brilliant results have been attained by hypnotic treatment, and in my own practice Ihave found no circumstance more gratifying and convincing than the rapid improvement which follows suggestion. 10. The treatment of dipsomania and the morphia habit by suggestion opens up quite a new field. In the case quoted, as much, if not more, effect followed a month's treatment as is generally expected from a year's esidence in a retreat. The Rev. Arthur Tooth of Croydon tells me that he is getting most gratifying results in his institution for dipsomaniacs from the systematic use of hypnotism.

Green-street, W.

\section{NEW SLIDING SPRING REPOSITOR.}

BY ALEXANDER DUKE, F.K.Q.C.P.I.,

EX-ASSISTANT MASTER, ROTUNDA HOSPITAL; GYNECOLOGIST, STEEVENS' HOSPITAL, DUBLIN.

PLUGGING the cervical canal in cases of serere hæmorwhage (other than post partum) will be found more effectua and much more comfortable to the patient that the older method of plugging the vagina. The want of a simple means for completely and firmly filling the cervical canal has long been felt, but $I$ think it will be found an easy matter by means of the instrument illustrated. It is simply an improved form of sliding repositor, the difference is that instead of the cannula being pushed forwards on the rod, the latter is made to retreat into the cannula by pressure of the

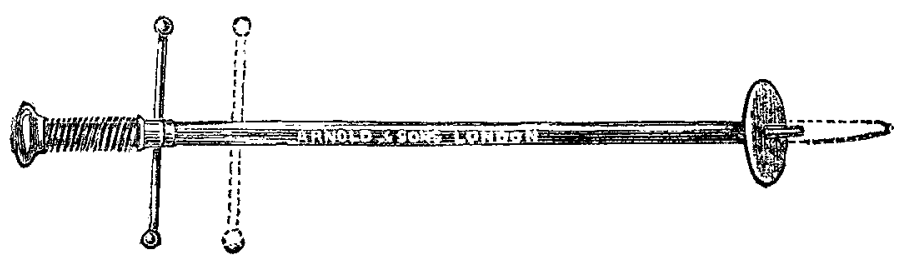

fingers on the projecting cross bars, and so the cotton plug with which the top of the rod is armed is pushed home into the cervix with ease and celerity. It may be urged that a sponge-tent or sea-tangle would be an easier mode of plugging the cervix, and quite as effectual; but besides the inconvenience of having to place a tampon of some kind in the ragina as well, in order to retain the tangle or tent till swollen enough to retain its hold, we have also the great liability to sepsis, and I certainly prefer being on the safe side. The size of the os being determined by digital examination, a piece of absorbent cotton is to be neatly, but not too tightly, wound round the projecting part of the rod (which measures about two inches in length) and thickly enough to fill tightly the cervical canal, or a short piece of round lamp wick can be drawn down on the point of the stylet and used instead if the operator prefers. The cotton plug, or wick, is then to be saturated with some antiseptic styptic; a saturated solution of alum in glycerine, Churchill's tincture of iodine, or turpentine; but I have a strong objection to iron in any form. A largesized cylindrical speculum is now passed, and the os and cervix syringed through speculum till all clots are removed. The cervix is then to be steadied with the tenaculum or the volsellum, held in the left hand, while the repositor, armed

1 Revue de l'Hypnotisme, Feb. 1889. with a plug, is introduced with the right; and on pressure being nade on the side bars of the instrument the plug is firmly pushed home into the canal, and the speculum and repositor withdrawn. Thus the whole operation can be done without assistance. If the plug is of the right dimensions (which of course inust depend on the judgment and experience of the operator), there need be no cause for anxiety, and the antiseptic and astringent properties of the lotion with which the plug was saturated should keep all sweet till expelled by uterine action, thus differing materially from sponge-tent or sea-tangle, which always gives rise to a certain amount of anxiety in the mind of the practitioner the longer it remains in utero.

The repositor will also be found useful (as it has been in its original form by the American gynæcologists) for depositing small pieces of cotton wool soaked in sone caustic colution in the cervix in the treatment of chronic endometritis, and the leaving of such in the cervical canal need not give the least anxiety to the doctor, as they are sure to be expelled by uterine action, as indeed any substance lying unattached in either the cavity or neck of the womb is bound to be. Messrs. Arnold and Sons, London, are the makers of the repositor, and the instrument on trial will be found a useful addition to the every. day armamentarium of the gynæecologist. Dublin.

\section{STATISTICS OF PERINEAL LATERAL AND MEDIAN LITHOTOMY :}

BEING OPERATIONS PERFORMED ON MALE INFANTS AND BOYS IN THE WOLVERHAMPTON AND STAFFORDSHIRE GENERAL HOSPITAL FROM 1864 TO 1888.

BY T. VINCENT JACKSON, F.R.C.S. ENG.

A FEW months ago my friend Mr. Reginald Harrison wrote to me with a request that I should supply Professor S. W. Gross, of Philadelphia, with a tabulated statement of all the cases of lateral and median lithotomy performed on infants and boys up to fifteen years of age in the Wolverhampton and Staffordshire General Hospital. Mr. Gough, house surgeon, at some trouble grouped together all these particular cases of operation from the hospital books, and the list was forwarded to Professor Gross; but his lamented death soon afterwards having doubtless prevented its publication, I feel that, as the record is one of practical interest and value, I ought no longer to refrain from making it known.

Cases of Lateral and Median Lithotomy from 1864 to 1888 , inclusive.

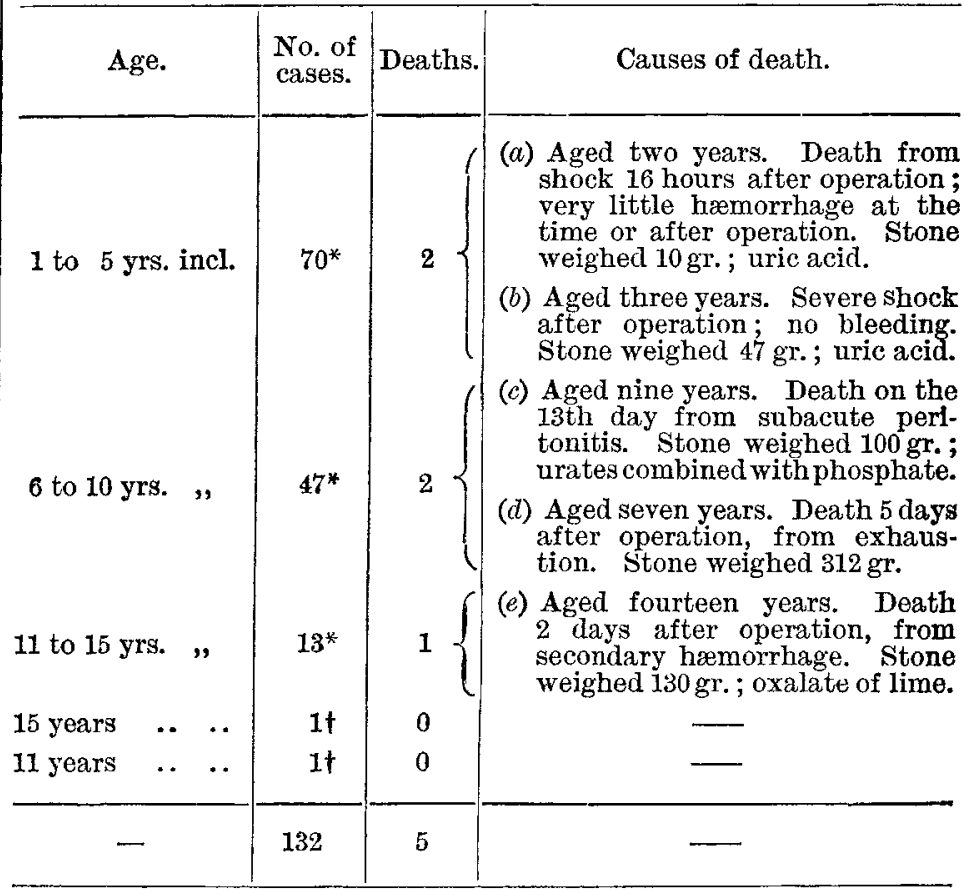

* Lateral lithotomy.

† Median lithotomy.

The above table indicates that during a period of twenty. four years 132 perineal operations for stone in the bladder of boys, varying in age from one to fifteen years, have been 